\title{
A REVIEW OF LAST DEVELOPMENTS IN THIN FILMS PARAMETERS OF DIRECT CURRENT SPUTTERING FOR OPTICAL AND BIOMEDICAL APPLICATIONS
}

\author{
AKRAM JASSIM JAWAD ${ }^{1,2 *}$ \\ ${ }^{1}$ University of Babylon, College of Materials Engineering, Department of Polymer and Petrochemicals Industrials Engineering, Al Hillah, \\ Iraq. ${ }^{2}$ Queen Mary University of London, School of Engineering and Materials Science, London, UK. Email: akrammaterials4@gmail.com
}

Received: 09 February 2021, Revised and Accepted: 13 March 2021

\section{ABSTRACT}

Nano thin films and nano coating have been applied in different fields in health care system because of their higher antiviral properties. Additionally, as the world have suffered since December 2019 from Covid-19 situation, different scientists and industrials people have tried to apply nano antiviral films and coatings in our daily life. In this short review, nano thin film coating procedure by DC sputtering technique has been reviewed, investigated, and evaluated by using different materials and device parameters in recent years. This report focuses on device factors that affect the thickness of nano-thin films for optical and optic-electric applications. These parameters including time, temperature, power, pressure, and flow rate of gases. The review provides more understanding meaning of the coating procedure by DC sputtering process.

Keywords: Direct current sputtering, Coating, Nano-thickness, Films.

(C) 2021 The Authors. Published by Innovare Academic Sciences Pvt Ltd. This is an open access article under the CC BY license (http://creativecommons. org/licenses/by/4.0/) DOI: http://dx.doi.org/10.22159/ijms.2021v9i3.41048. Journal homepage: https://innovareacademics.in/journals/index.php/ijms

\section{INTRODUCTION}

Nano-film thickness of metals coating on polymer substrate plays an important issue in direct current (DC) sputtering techniques for many technical advance applications, such as optical coatings, biomedical, surface, and electronic applications [1-3]. For example, the antibacterial ability of nano-thickness Cu film manufactured by DC sputtering was investigated to be higher more than 3 times [4]. Thickness can affect coating properties such as shielding against electromagnetic, ultraviolet (UV) resistance, electrical conductivity, antibacterial ability, and so on [5,6]. Kylián et al. (2014) illustrates an example of the deposition of nano-thickness of $\mathrm{Cu}$ thin film coatings on polymer substrate [3] Oh et al. (2016) studies the relationship between the Argon plasma and surface bonding of treating the Ajinomoto build-up film surface [7]. Zakharova et al. (2012) investigated the effect of Cu coating nanothickness on transparency ability for the visible light, it shows that there are transparency and reflection enhancement of about $60 \%$ and $84 \%$, respectively [8]. There are many factors in the nano-film coating procedure in DC sputtering that can affect the thickness and coating related properties which including optical and optic-electric properties $[3,5,7]$. These parameters may belong into materials characteristics that used in the coating process, such as type and compositions of target and substrate materials. These types of parameters have been evaluated and it is in progressing and has many different disciplines sector studies. Alternatively, the another factors may belong to device ability and designs, for instance, the distance and angle between substrate and target, voltage and current capacity, cooling and gas systems efficiency, and chamber pressure permeability.

This group has been more opportunity to achieve development in the coating procedure by DC sputtering, especially for optical properties. These characteristics including transmittance, reflectance, and absorption spectra of UV and Visible light (UV-VIS) in wavelength about $(200-800) \mathrm{nm}$ that have been investigated in recent works $[2,6]$.

The objective of this report will be to present, evaluate, and analyze the recent developments in parameters that affect the nano-film coating procedure by DC sputtering technique. However, it will be more focused on time, temperature, pressure, power, and flow rate factors than others because they have more attention in recent years and they have more significant role in that procedure. Moreover, the attention will be more on the effect of these factors in the sense of optical and electrical properties, especially the optic-electric characteristics for electrical applications. To achieve that, this report has been organized into different parts, namely, methods, procedures, results and discussions, and conclusion. First, a simple explanation of standard DC sputtering device components will be introduced in the methods section. Then, clarifying in detail the coating procedure by DC sputtering will be explained in the procedure section. After that, the more recent development and results of time, temperature, pressure, power, and flow rate factors on the optical and related electrical properties with evaluation and analysis will be selected and discussed in the results and discussion section.

\section{METHODS}

The main components of DC sputtering technique including the main device, pump, and gas system [9]. The main device contains all the electrical parts such as the voltage system to generate high voltage current, water system for cooling DC sputtering parts during the coating process. Furthermore, the heating system control of substrate temperature, the chamber that including target and substrate, and pipe line nets to vacuum and inject an inert gas from the outer bottle, usually argon or nitrogen gas, into the chamber under controlling pressure by the pump. There are different collections of target and substrate configuration inside the chamber sputtering. Some designs have that in a vertical, horizontal, or angular level, as shown in Figs. 1 and 2 [9]. In addition to that, in some, there is more than one target material to produce different composites materials.

\section{Procedures}

There are different coating procedures by DC sputtering that depend on the device type, organization, and automatic operation level that have been written in the last few years [6,7,9]. Gobbl et al. (2013) presented a simple procedure of nano-film coating by horizontal and vertical organization DC sputtering with comprehensive details of parameters, as shown in Fig. 3 (9, p 701). This procedure contains many steps, and these steps make the main differences between different procedures. However, these differences could be eliminated by making a general development in those parameters, such as generalization of substrate 
temperature which may produce similar procedures for the heating process for different coating materials.

There is a wide range of parameters that control the coating process in DC sputtering which lead to make this technique quiet complex. These parameters including materials properties, which maybe have more ability for developing process, and device factors, which have limited improvement ability. It seems that the enhancement in DC procedure could achieve in the materials characterizes because it has more flexibility to design and selection materials for any possible and appropriate application. On the other hand, if device factors need to be in a line of developing process of coating procedure, it might need more time and more advanced technology, as well as changes in design and configuration of devices, which in fact depend on materials choosing. Therefore, it is supposed that target, substrate temperature, compositions, and type of substrate, and target materials may have more attention in the next few years. However, the current research focus on voltage, current, gas pressure, the distance between target and substrate, gas flow rate, and gas content.

\section{RESULTS AND DISCUSSION}

Sputtering time is a challenging part of the developing process in DC sputtering procedure. There are a number of studies that focused on this factor to make the technique more economical and applicable in industrial fields. For example, Zhanga et al. (2016) focus on the effect of

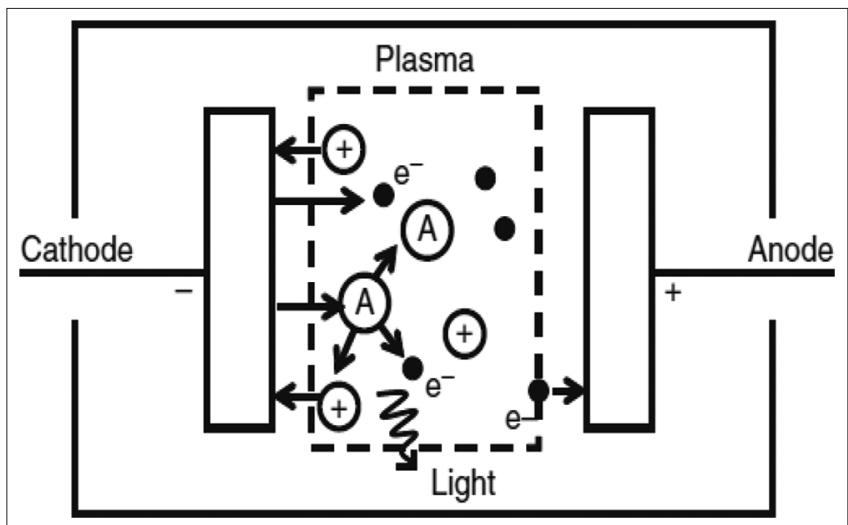

Fig. 1: A smile schematic of the plasma formation principle between cathode and anode [9]

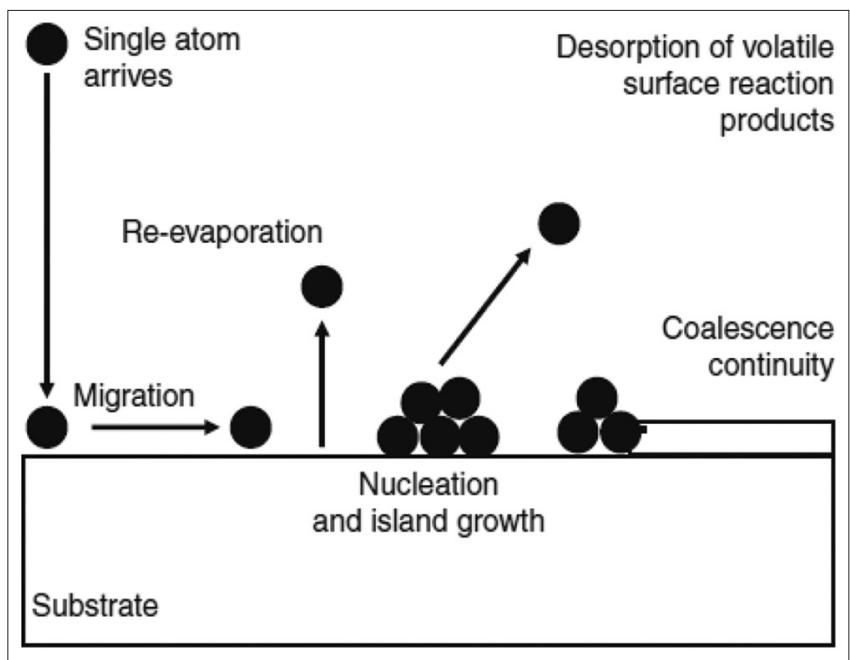

Fig. 2: A schematic of the main stages to format nano-films by direct current sputtering [9] sputtering time parameter on nanoshell optical properties of $\mathrm{TiO}_{2} / \mathrm{ZnO}$ that used in solar cell applications [10]. Fig. 4 shows the relationship between UV-VIS absorption of nanoshell MS ZnO on Rutile substrate, and DC sputtering times for wavelength range between 200 and $700 \mathrm{~nm}$ $(10, p 5)$. The results prove that there is an enhancement in the optical properties with short sputtering times, about 3-15 min. That is mean there is high ability to develop DC sputtering procedure with shorter sputtering times in the next few years to be applicable in industrials sectors. In addition to that, Aragóna et al. (2017) characterize films of $\mathrm{SnO}_{2}$ by DC sputtering at different sputtering times in terms of electrical and morphological properties [11]. This gives a wide view of how sputtering times effect not just on optical characterization but also on different properties.

The operating temperature factor has a significant role in the approximated proposed age of devices, especially in the highly advanced techniques that are operated in a high environment of temperature such as DC sputtering. As a result of that, many authors investigate the enhancement in the temperature factor to minimize it as much as possible which leads to the high quality of nanofilms coating and shorter time of device maintenance. Park et al. (2012) studied the impact of temperature of substrate on the DC sputtering procedure of Ga-doped ZnO nanofilms coating for electrical uses [12].

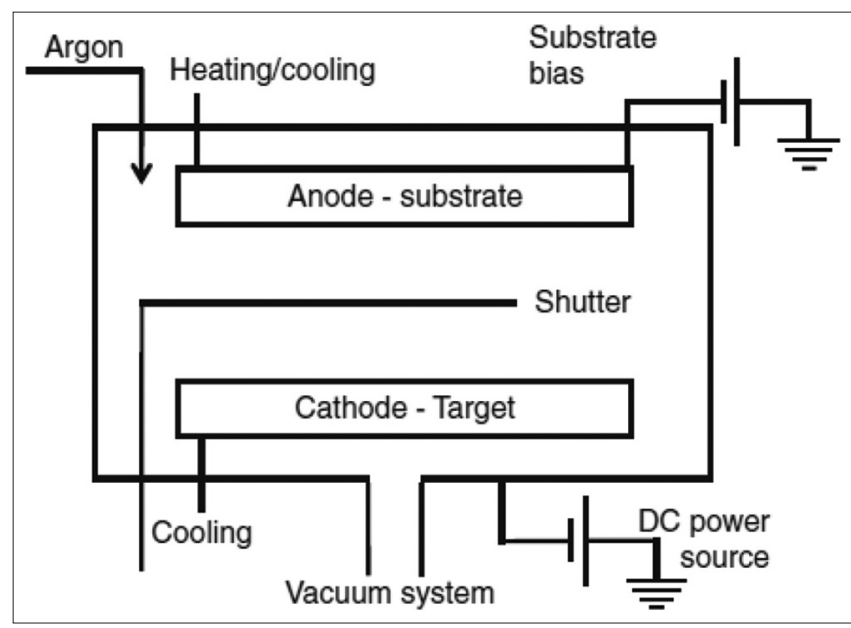

Fig. 3: A schematic of direct current sputtering chamber with the main and important factors that effect on the process [9]

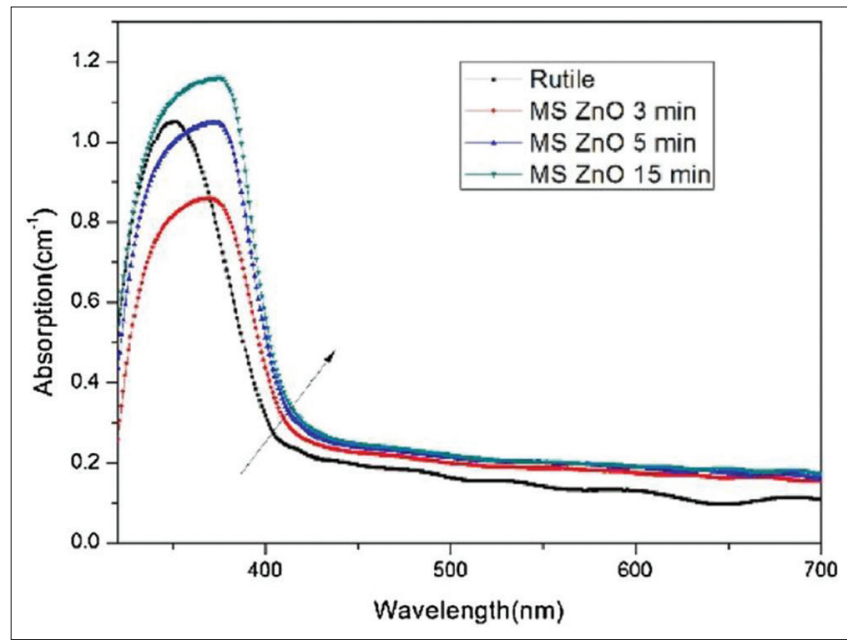

Fig. 4: The relationship between ultraviolet visible absorption and sputtering times (3-15) $\mathrm{min}$, for wavelength range between 200 and $700 \mathrm{~nm}[10]$ 
Fig. 5 shows the relationship between transmittance spectra of UVVIS between (200 and 800) nm of Ga-doped $\mathrm{ZnO}$ nano films with different substrate temperatures $\left(25,75,150\right.$, and $\left.230^{\circ} \mathrm{C}\right)(12, \mathrm{p} 4)$. The results provide high conservation of the consumption energy approach by minimizing substrate temperature which was $75 \mathrm{c}$ as an optimal operation temperature, as well as decreasing maintenance time of high-temperature problems. Moreover, the electrical efficiency of these coating in electrical applications like in solar cells will increase compared with traditional coating as a results of high transmittance ability.

The pressure factor considers an important factor in any procedure of advanced technology such as in DC sputtering as a result of a critical its effect on the price, quality, and safety of the devices. Since DC sputtering technique was discovered, there have been many redesigning, re-planning, and studies of coating procedures by DC sputtering technique to minimize and manage the high pressure uses, especially in the last few years. For example, Hsua et al. (2013) studied the effect the pressure in DC procedure on the optical characteristics of nano-thin films for electrical applications [13]. Fig. 6 illustrates the transmittance spectra of UV-VIS radiation in the range of wavelength (200-900) nm of $\mathrm{Al}-\mathrm{Y}$ co doped $\mathrm{ZnO}$ nanofilms at different ranges of DC sputtering pressure $(5,7,11$, and 13) mTorr (13, p 4). This figure provides a significant decrease in the pressure range in DC sputtering procedure that might be applicable in a wide range of industries fields, especially electric and optic-electric applications and products. Moreover, it seems that in the next few years there are high opportunities to manufacture small devices of DC sputtering at lower prices compared with the current one.

One of the most important factors is the mixture and content of gases in sputtering chamber, especially oxygen percentage. Consequently, studying ratios of oxygen in sputtering chamber has been achieved in a number of experimental studies under different conditions due to the effect of oxygen ratio on the safety and quality of nano-thin films. For instance, ABE et al. (2005) investigated the effect of oxygen content in Argon based gas to fabricate nano-thin films of amorphous indium tungsten oxide and studied its optical related properties [14]. Fig. 7 represents the spectra of transmittance and reflectance of UV-VIS radiation for wavelength between $200 \mathrm{~nm}$ and $2600 \mathrm{~nm}$ of amorphous indium tungsten oxide nanofilms at a different range of oxygen ratios inflow of sputtering gas $(0.5,1,1.5$, and $2 \%)[14, \mathrm{p} 3]$. This figure shows

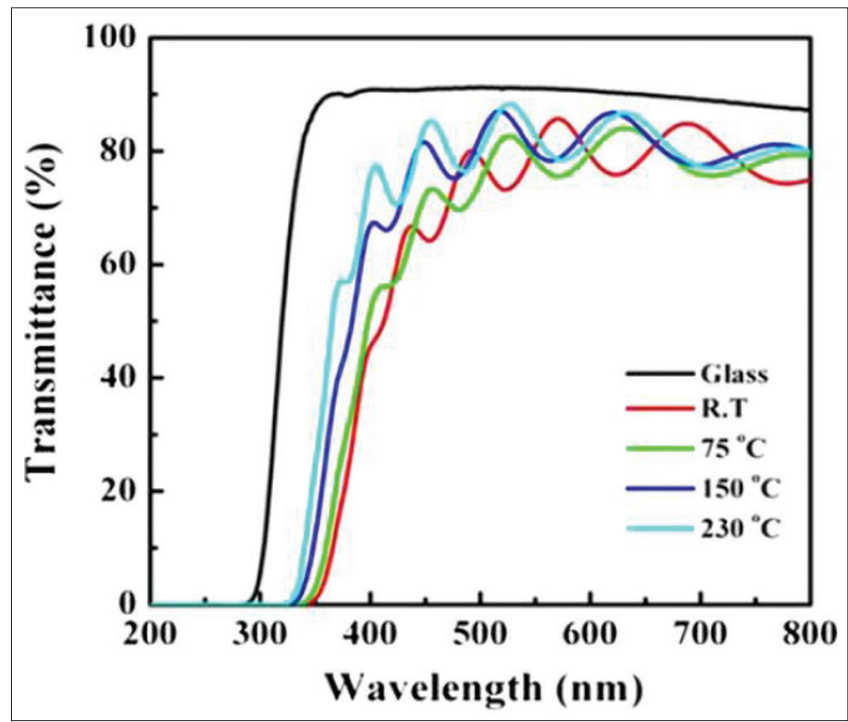

Fig. 5: The relationship between transmittance spectra of ultraviolet visible between 200 and $800 \mathrm{~nm}$ of Ga-doped ZnO nanofilms with different substrate temperature $(25,75,150$, and $\left.230^{\circ} \mathrm{C}\right)[12]$ that there is an enhancement in the transmittance and reflectance of prepared nano-thin films as the oxygen ratios in sputtering gas decreasing.

Power consumption plays a crucial factor in success opportunities in any technical process, especially with high consumption advanced technology like DC sputtering. Therefore, there are many attempts in the last few years that have been tried about effect power factor on different properties of nanofilms, in particular optical properties. For example, Rashida et al. (2019) study the effect of power factor on optical characteristics of molybdenum nanofilms for electrical applications [15]. Fig. 8 illustrates the relationship between the reflectance spectra of UVVIS radiation and DC sputtering power in the range of 100,150, and 200 watts, for wavelength between 200 and $150 \mathrm{~nm}(15, \mathrm{p} \mathrm{6})$. The obtained results provide a significant improvement in energy consumption of coating by DC procedure because there are more acceptable optical properties in the lower DC sputtering power compared with higher

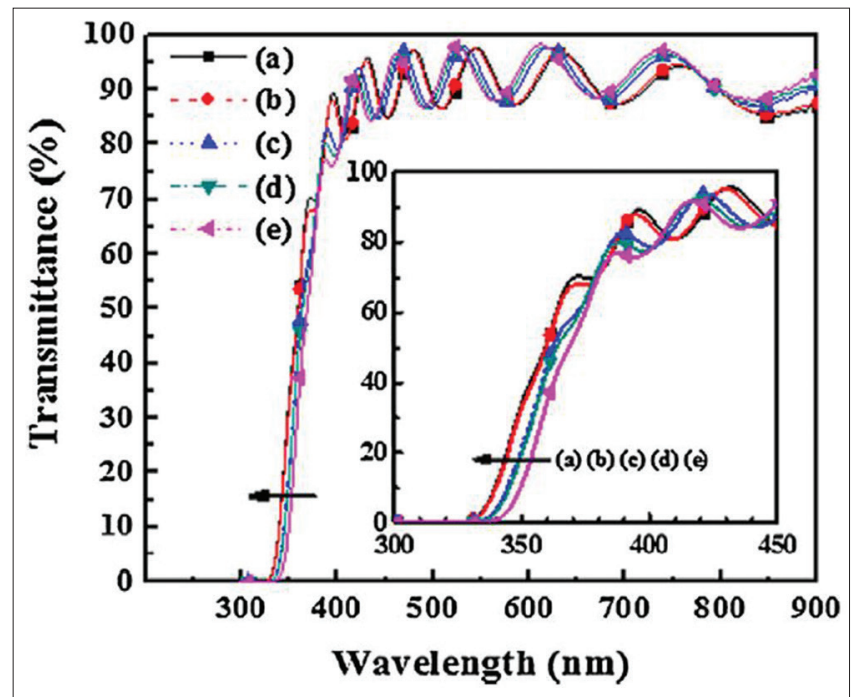

Fig. 6: Transmittance spectra of ultraviolet visible radiation for wavelength (200-900) $\mathrm{nm}$ of Al-Y co doped ZnO nano-thin films at different range of direct current sputtering pressure $(5,7,11$, and 13) mTorr [13]

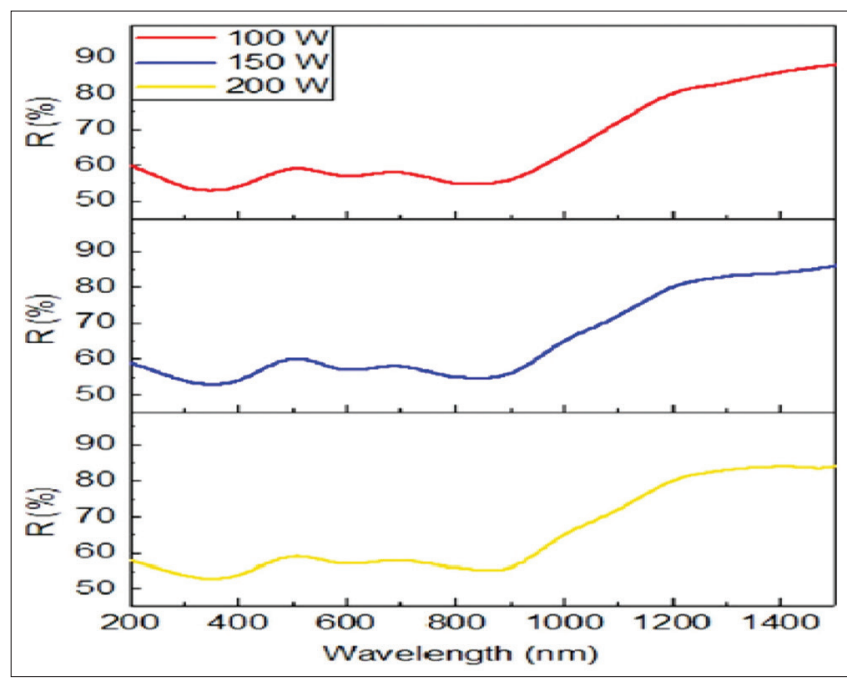

Fig. 7: Spectra of transmittance and reflectance of ultraviolet visible radiation for wavelength between $200 \mathrm{~nm}$ and $2600 \mathrm{~nm}$ of amorphous indium tungsten oxide nano-films at different range of oxygen ratios in flow of sputtering gas $(0.5,1,1.5$, and $2 \%)[14]$ 


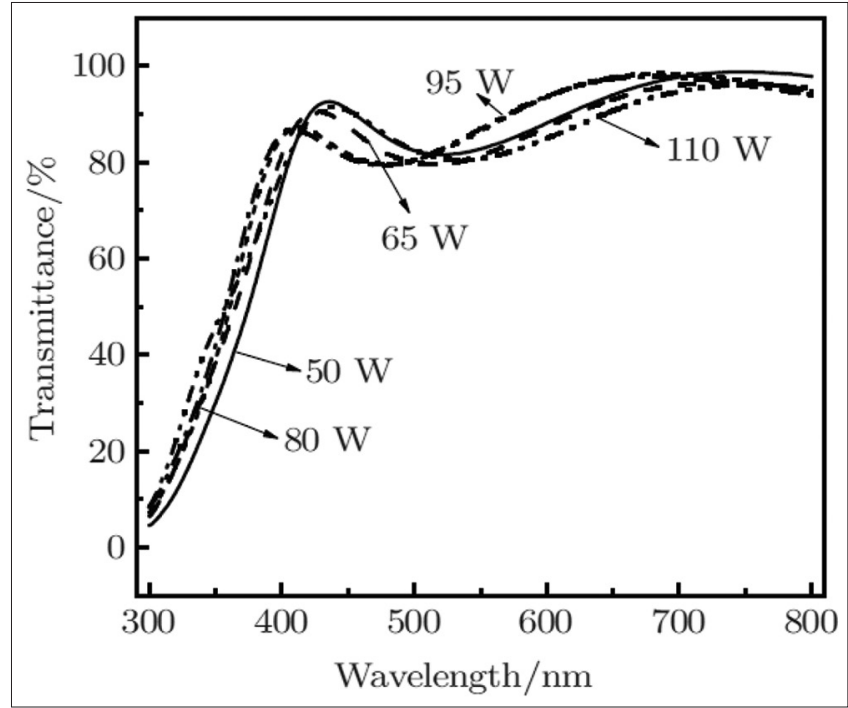

Fig. 8: Reflectance of ultraviolet visible spectra of molybdenum nano-films at different values of direct current sputtering power $(100,150$, and 200$)$ watts [15]

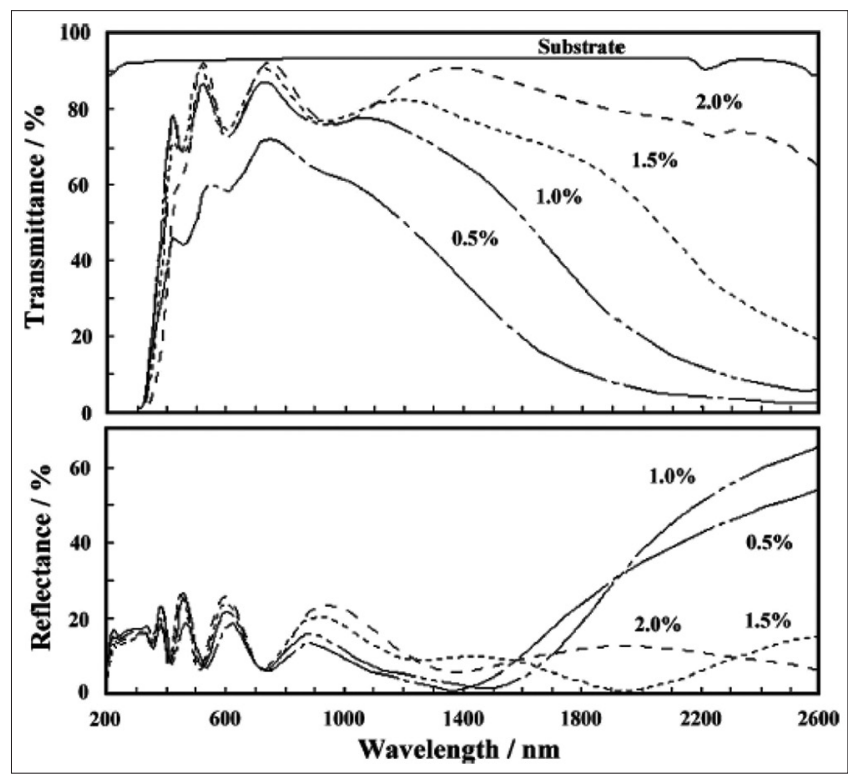

Fig. 9: Transmittance spectra of ultraviolet visible radiation for 300-800 $\mathrm{nm}$ of indium tungsten oxide nano-films at different values of direct current sputtering power $(50,65,80,95$, and 110) watts [16]

values, especially for optic-electric properties such as anti-reflectance coating in solar cells applications. Other findings were obtained of the effect DC sputtering power on the transmittance property [16]. Fig. 9 represents the transmittance UV-VIS spectra of Indium-tin oxide nanofilms with different range of DC power $(50,65,80,95$, and 110$)$ watts for wavelength between 300 and $800 \mathrm{~nm}(16, \mathrm{p} 3)$. These results give an opportunity to make DC sputtering more economic in the next few years to be used in a wide range of daily and high use products.

\section{CONCLUSION}

In summary, the recent developments of parameters in the last few years that effect on coating procedure by DC sputtering have been presented, evaluated, and discussed. It has found that there is a significant enhancement in the sputtering time to be shorter which enables the coating process to be more effective and efficient. The consumption of energy in terms of power and substrate temperature has been developed to be at a lower level in recent years compared with the old DC sputtering procedure when it is stared to use. Furthermore, investigation of the effect of gases content in the sputtering chamber has been reported especially for oxygen ratios, which gives a high indicator for optimum quality of nano-thin films in low percentage of oxygen in Argon based gases. Finally, the relationship between pressure factor and optical properties has been reviewed in the sense the recent developments and its effect on optic-electric properties. These improvements in that parameters might give a chance to produce high quantity and quality in small size space with lower prices. Therefore, these findings may encourage to make DC sputtering in a simple procedure to be more familiar in all educational, researcher, and industrial sectors.

\section{REFERENCES}

1. Dornhof J, Urban GA, Kieninger J. Deposition of copper nanofilms by surface-limited redox replacement of underpotentially deposited lead on polycrystalline gold. J Electrochem Soc 2018;166:D3001.

2. Beyene HT, Tichelaar FD, Verheijen MA, van de Sanden MC, Creatore M. Plasma-assisted deposition of $\mathrm{Au} / \mathrm{SiO}_{2}$ multi-layers as surface plasmon resonance-based red-colored coatings. Plasmonics 2011;6:255-60.

3. Kylián $\mathrm{O}$, Kratochvíl J, Hanuš J, Polonskyi $\mathrm{O}$, Solař P, Biederman $\mathrm{H}$. Fabrication of $\mathrm{Cu}$ nanoclusters and their use for production of $\mathrm{Cu} /$ plasma polymer nanocomposite thin films. Thin Solid Films 2014;550:46-52.

4. Liu Y, Leng J, Wu Q, Zhang S, Teng X. Investigation on the properties of nano copper matrix composite via vacuum arc melting method. Mater Res Express. 2017;4:106512.

5. Ehiasarian A, Pulgarin C, Kiwi J. Inactivation of bacteria under visible light and in the dark by $\mathrm{Cu}$ films. Advantages of $\mathrm{Cu}$-HIPIMS-sputtered films. Environ Sci Pollut Res 2012;19:3791-7.

6. Jia ZN, Hao CZ, Yang YL. Tribological performance of hybrid PTFE/ serpentine composites reinforced with nanoparticles. Tribol Mater Surf Interfaces 2014;8:139-45.

7. Oh Y, Kim EJ, Kim Y, Choi K, Han WB, Kim HS, et al. Adhesion of sputter-deposited $\mathrm{Cu} / \mathrm{Ti}$ film on plasma-treated polymer substrate. Thin Solid Films 2016;600:90-7.

8. Zakharov AN, Kovsharov NF, Oskomov KV, Rabotkin SV, Solovyev AA, Sochugov NS. Properties of low-emission coatings based on $\mathrm{Ag}$ and $\mathrm{Cu}$ deposited on polymer film by magnetron sputtering. Inorg Mater 2012;3:433-9.

9. Wang QJ, Chung YW. Encyclopedia of Tribology. Berlin: Springer; 2013.

10. Zhang Z, Hu Y, Qin F, Ding Y. DC sputtering assisted nano-branched core-shell $\mathrm{TiO}_{2} / \mathrm{ZnO}$ electrodes for application in dye-sensitized solar cells. Appl Surf Sci 2016;376:10-5.

11. Aragón FH, Aquino JC, Gomes NC, Ardisson JD, da Silva SW, PachecoSalazar DG, et al. Characterization of polycrystalline $\mathrm{SnO}_{2}$ films deposited by DC sputtering technique with potential for technological applications. J Eur Ceramic Soc 2017;37:3375-80.

12. Park JH, Shin BK, Moon HM, Lee MJ, Park KI, Ahn KJ, et al. Effect of the substrate temperature on the properties of Ga-doped $\mathrm{ZnO}$ films for photovoltaic cell applications deposited by a pulsed DC magnetron sputtering with a rotating cylindrical target. Vacuum 2012;86:1423-7.

13. Hsu FH, Wang NF, Tsai YZ, Chuang MC, Cheng YS, Houng MP. Study of working pressure on the optoelectrical properties of Al-Y codoped $\mathrm{ZnO}$ thin-film deposited using DC magnetron sputtering for solar cell applications. Appl Surf Sci 2013;280:104-8.

14. Abe $\mathrm{Y}$, Ishiyama $\mathrm{N}$, Kuno $\mathrm{H}$, Adachi $\mathrm{K}$. Amorphous indium tungsten oxide films prepared by DC magnetron sputtering. J Mater Sci 2005;40:1611-4.

15. Rashid H, Rahman KS, Hossain MI, Nasser AA, Alharbi FH, Akhtaruzzaman $\mathrm{M}$, et al. Physical and electrical properties of molybdenum thin films grown by DC magnetron sputtering for photovoltaic application. Results Phys 2019;14:102515.

16. Jin-Hua G, Jia-Le S, Jiu-Xiu W, Ya-Yang F, Xiao-Yong G, Jing-Xiao L. Indium-tin oxide films obtained by DC magnetron sputtering for improved Si heterojunction solar cell applications. Chin Phys B 2015;24:117703. 